\title{
Model uncertainty, political contestation, and public trust in science: Evidence from the COVID-19 pandemic
}

\author{
S.E. Kreps and D. L. Kriner* \\ Department of Government, Cornell University, Ithaca, NY, USA. \\ *Corresponding author. Email: kriner@cornell.edu
}

While scientific uncertainty always invites the risk of politicization and raises questions of how to communicate about science, this risk is magnified for COVID-19. The limited data and accelerated research timelines mean some prominent models or findings inevitably will be overturned or retracted. In this research, we examine the attitudes of more than 6,000 Americans across five different survey experiments to understand how the cue giver and cue given about scientific uncertainty regarding COVID-19 affect public trust in science and support for science-based policy. Criticism from Democratic political elites undermines trust more than criticism from Republicans. Emphasizing uncertainty in projections can erode public trust in some contexts. Downplaying uncertainty can raise support in the short-term but reversals in projections may temper these effects or even reduce scientific trust. Careful and effective science communication is critical to maintaining public support for science-based policies as the scientific consensus shifts over time.

\section{Introduction}

In March 2020, Imperial College offered one of the earliest projections of COVID-19 deaths around the world, predicting 2.2 million fatalities in the United States (1). The forecast became a guide for public policy and a key impetus for aggressive measures to control the virus' spread, including closures of schools and places of worship, a pause on significant commercial activity, and travel bans.

Because of their role in the policy process, impact on citizens' lives, and apparent erroneous projections, models predicting the course of the COVID-19 epidemic have become a flashpoint for debate about the proper role of science in the policymaking process. Referring to the Institute for Health Metrics and Evaluation (IHME) model that was an important basis for the Trump Administration's public health guidelines, Marc Lipsitch of Harvard's School of Public Health questioned whether the model was "well suited" to the task of predicting COVID-19 fatalities. An epidemiologist from the Fred Hutchinson Cancer Center questioned whether the model should be used to guide policy decisions given that small errors in one of the assumptions could and did produce enormous and potentially erroneous projections (2). Before long, criticism of models had become a cable news mainstay. In early April, Fox Neres host Tucker Carlson denounced epidemiological models and those preaching reliance on them: "At this point, we should not be surprised that the model got it wrong... [they are] completely disconnected from reality"(3).

Scientific uncertainty regularly invites political manipulation and debates about communicating complicated and consequential models to the public (4). Scientific models in particular are frequent subjects of political contestation, as in the case of climate change, because they are inherently uncertain and built on abstractions about the theorized relationship between cause and effect, complicated feedback loops, and missing variables or data (4). Models therefore are not "true/false but better/worse, and the possible discrepancy regarding the problem or its parts can have several plausible explanations" (5).

COVID-19, as a novel coronavirus, is defined by uncertainty. This is perhaps most readily apparent in models predicting the virus' spread, which have been plagued by limited data and the emerging scientific assumptions about transmission and public health interventions. Problems with virologic testing made the actual number and spread of infections unknown, and models were fitted to data on confirmed cases that vary spatially and over time, leading to projections that proved wildly inaccurate (6). For example, the IHME model projected US fatalities based on data from cities where the virus had struck, meaning Wuhan and cities in Spain and Italy. The model fared reasonably well for New York but across other states in the US, actual deaths for a given point in time fell outside the IHME model's $95 \%$ posterior interval between 49 and $73 \%$ of the time (7). One clinical physician quoted in a widely-shared Science article said "we need to keep a very open mind as this phenomenon goes forward. We are still learning" (8). Scientists understand the uncertainties embedded in models, but because of the direct public health stakes, the models took center stage in public discourse, with political elites and the media communicating complex and 
uncertain science to a lay audience.

The inevitable reversals in scientific recommendations constitute another manifestation of underlying uncertainty vulnerable to contestation. The speed with which the pandemic spread across the globe triggered an international race to understand the virus and how to combat it. Researchers responded with studies and findings within days and weeks instead of the usual months or years. The inevitable result was that the scientific "consensus" shifted as new data emerged, presenting challenges to policymakers trying to craft public health measures while also providing clear and consistent guidance to citizens.

While past studies have generally shown how critics can exploit uncertainty to lower support for science-based policy interventions in prominent policy debates from climate change, to linkages between tobacco and cancer, and nuclear power $(9,10)$, there are important reasons to question whether these insights apply to COVID-19. In the current context, the science is far more unsettled, and its potential consequences for the public more immediate. The incentives for politicization by political elites may also be even higher today given the highly disruptive policy consequences of COVID-19 interventions such as lockdowns. For media elites, the stark uncertainty combined with the considerable urgency to report results creates new ambiguities about how to communicate complexity to the public. Media coverage can explicitly acknowledge the unknowns in model projections and COVID-19 science more generally; ignore this uncertainty and paint an unrealistically deterministic portrait of model predictions and the scientific consensus at a given moment; or can go further and "catastrophize" the consequences of not heeding the science. How these competing communications, in turn, shape public support for science-based policy responses to the pandemic and trust in science more generally is the focus of this research.

To theorize about political contestation around COVID-19 science, we develop and empirically test hypotheses about the effects of scientific communication on public opinion having to do with both the identity of the cue giver and the substance of the cue itself. First, we advance an argument based on the characteristics of the cue giver. Specifically, we hypothesize that both elite criticism and support for models have differential impacts depending on the public's priors about the cue giver. Second, we develop a set of hypotheses about the nature of the cue given and whether the uncertainty is ignored, acknowledged, or highlighted and weaponized, and with what effect.

We then test the cue giver and cue given arguments with five original survey experiments. We find that political criticism of COVID-19 models can undermine support for their use and trust in science - but only criticism from Democrats. These results speak to the delicate balance Democratic politicians must strike when publicly engaging COVID-19 science. We find that acknowledging and explaining the uncertainty embedded in models does not increase trust for science and its role in policy-making; we also find conditional evidence that criticism of COVID-19 science emphasizing uncertainty can erode public confidence in some contexts. Communicating the science in ways that are more categorical, sidestep uncertainty, and weave in fatalistic interpretations of the data are effective at building support at least in the short term. However, if projections prove incorrect, arguments emphasizing reversals in projections can temper such gains and potentially even decrease support for science-based policymaking.

\section{Effects of the cue giver}

The Imperial College model projecting American and British fatalities was the first to guide policy, but models quickly proliferated, becoming the focal point for policy decisions about public health and the economy and attracting both praise and derision from policy makers. In New York, Democratic Governor Andrew Cuomo invoked these projections in his daily briefings, heeding the urgings of one Imperial College scientist advising the Governor to "follow the science." In contrast, Florida Governor, Republican Ron DeSantis, whose approach was emblematic of a more dismissive approach to science in guiding decisions about reopening, also invoked the models, but disparagingly so, questioning whether "any of the models [had] been accurate so far." These public gubernatorial statements were representative of Republican/Democratic political elite divides on COVID-19 communication more generally. Green et al. show that Democrats in Congress were engaged earlier and more often on COVID-19 related health questions than Republicans, who were more likely to emphasize business and China in their communication (11).

Based on these modal themes in communication, we hypothesize that criticism of COVID-19 science and support for its use in guiding policy-making will have differential impacts depending on the public's priors about the cue-giver $(12,13)$. Specifically, we focus here on contra type signaling and hypothesize the public is more likely to infer that leaders are offering informative signals about models when they advance arguments that conflict with the signaling elite's expected type or ideological preferences (14). Accordingly, the contra type logic suggests that Democratic skepticism of the utility of COVID-19 models should significantly undermine public trust, while the same criticism from Republican elites will be less influential. By contrast, Republican endorsement of models should increase trust with the public because it is unexpected while Democratic support, which is expected, should be less influential. However, while most criticism of COVID19 models came from Republicans, pro-science public actions and statements of Republicans such as Governors Baker 
(Massachusetts), DeWine (Ohio), and Hogan (Maryland) offered counterweights. This split may render Republican support for COVID-19 models less unexpected and therefore less influential than Democratic criticism (15), which is the clearest contra type signal.

\section{Effects of the cue given}

We hypothesize that the substance of a cue also affects public attitudes and preferences. One type of cue, typically embraced by critics of policies relying heavily on scientific model predictions, emphasizes and exploits uncertainty in an effort to erode support for governmental action (16). Since models involve layers of uncertainty about the natural variability of a scientific process (how it changes over time), measurement errors and incomplete data, or abstractions that leave out important variables or interactions, critics can point to any one of these features seeking to highlight a model's indeterminacy and undermine the case for policy change (17). Seeking to influence public opinion on climate change, skeptics have sought to exploit uncertainty and articulate it in ways that spread doubt, undermine public confidence in climate science, and induce policy inaction $(9,18-21)$. If the skeptical cue (9) is effective in the COVID-19 context, then criticism emphasizing the uncertainty in model projections (e.g., conservative columnist Tucker Carlson's critique quoted previously) and in emerging COVID-19 science more generally would undermine support for science-based responses to the pandemic and perhaps also public trust in science more broadly.

Rather than maximize the uncertainty inherent in models, a second approach endeavors to ignore it, which can be manifested in two ways. The first is by offering a point prediction for the model rather than a range that explicitly recognizes the inherent uncertainty surrounding projections. For example, in May 2020, the IHME model predicted that by early August, the US would suffer a nationwide death toll of 134,475 , the figure that headlined most media accounts of the model. On its own website, however, the University of Washington acknowledged sources of uncertainty, such as social distancing behaviors that could affect transmission rates, and presented a range of projected deaths based on the model.

Another, even more extreme form of ignoring uncertainty is to "catastrophize" the consequences of inaction in the face of parlous scientific predictions (22). In the context of climate change, these narratives emphasized visceral symbols such as drowning polar bears, melting glaciers and polar ice, and hurricane devastation. The accessibility of narratives emphasizing the dire implications of inaction and downplaying the uncertainty of climate models may resonate with the public and mobilize trust at least in the short term (23). However, some scholars suggest that gliding over the uncertainty and complexity of science in favor of a clean narrative played into the hands of climate skeptics who then accused advocates such as $\mathrm{Al}$ Gore of "alarmism" unwarranted by the models (17).

Illustrative of such unqualified prognostication in the context of COVID-19 is an Atlantic headline warning of "Georgia's Experiment in Human Sacrifice" in reopening its economy faster than recommended by public health guidelines (24). Disregarding the considerable uncertainty in model projections, the Atlantic article implied a near certitude that Georgia's early reopening would lead to skyrocketing deaths, declaring the state's citizens "largely unwilling canaries in an invisible coal mine, sent to find out just how many individuals need to lose their job or their life for a state to work through a plague." While the stark projections may mobilize public cooperation, their uncertainty may mean they are later proven inaccurate, with potentially adverse impacts on the public's trust in science.

Finally, uncertainty need not be either weaponized or ignored. Rather, it can be communicated dispassionately, acknowledging the uncertainty, knowns and unknowns, ranges of probabilistic projections, and data imperfections in ways that are both more scientifically grounded and possibly more effective in terms of earning trust with the public. Most simply, rather than emphasizing point predictions, science communications can acknowledge uncertainty by presenting ranges that demonstrate the uncertainty surrounding an estimate. But this uncertainty can also be contextualized to educate recipients about the uncertainties inherent in emerging research on a novel phenomenon. Data analyst Nate Silver implicitly endorsed this approach for communicating about COVID-19 when he observed that "the data we have on coronavirus is highly imperfect and this sometimes leads to misleading conclusions" and the media should grant these uncertainties (25). Acknowledging uncertainty avoids the hyperbole and determinism that oversimplify scientific complexities (26) and guards against the potential backfire effect $(27,28)$ that may result from the catastrophizing cue should its deterministic projections be seen as biased or falsified in the face of contrary evidence. As a result, it may even shore up public support for science. On the other hand, openly conceding uncertainty, which indirectly gestures toward the model's limitations, may instead increase public skepticism. Raising the specter of the latter dynamic, it is notable that conservative news outlet Red State seized on Silver's tweet to warn of data manipulation (25).

\section{Results}

To evaluate the effect of the cue giver and cue given on public preferences concerning the role of science in shaping the policy response to COVID-19 in particular and attitudes toward science more generally, we carried out a series of five original experiments. For each of these experiments, we examined 
two dependent variables. The first specifically measured public support for relying on COVID-19 models to guide economic reopening decisions. The second was an additive index constructed from three measures of popular support for science more generally. The first question measured public beliefs that scientists should play an active role in shaping science policy (29). The second measured public confidence in science to act in the public interest (30). The third queried public beliefs about whether scientists' judgements are unbiased, or just as likely to be biased as those of other people (31). The resulting index ranged from 0 to 3 and offers a broad measure of trust in science, which is critical in shaping whether individuals will heed public health guidelines versus overriding them with their own prescriptions that may harm themselves or the community (32).

\section{Study 1: Partisan elite cues experiment}

The first experiment examined the influence of partisan elite cues about COVID-19 models on popular beliefs and attitudes. On May 2-3, 2020, we examined the responses of 2,038 Americans to vignettes about the proper role of COVID-19 epidemiological models in the policy process. Subjects were randomly assigned to one of six experimental conditions that varied endorsement or criticism of models and the partisan identity of the cue-giver (Democrat/Republican/or Democrat and Republican Governors) or to a control that did not provide any prompt about the role of models or partisan cue.

In impugning the accuracy of model predictions, the critical treatments implicitly seized upon the uncertainty inherent in the models and dispensed of their policy utility. For example, in the Democratic criticism treatment, subjects were told: "Some Democratic Governors have questioned the accuracy of these models. In a recent interview, one Democratic Governor said, "Decisions about reopening the economy need to be based on common sense and state-specific features, not scientific models." The Republican criticism treatment used identical language but identified the Governors as Republican. The bipartisan criticism treatment was also identical, but stated that "some Democratic and Republican Governors" questioned the accuracy of COVID-19 models and attributed the quote about not relying on models to guide reopening to a recent interview involving "two Governors, one Democrat and one Republican."

The three supportive treatments again varied the partisan identity of the Governors (Republican/Democrat/or from both parties) but stated that these Governors "endorsed the accuracy" of COVID-19 models and argued that "Decisions about reopening the economy need to be based on evidence and the best evidence we have is the scientific models."

Figure 1 presents the difference in mean support along each dimension between each experimental condition and the control group. I-bars present $90 \%$ confidence intervals around each difference in means. Figure 1 first plots the estimated effect of each treatment among all subjects. However, because the effects of partisan elite cues should logically also vary by the partisan affiliation of the cue recipient (12), Fig. 1 also plots the estimated treatment effect among self-identified Democrats and Republicans.

Perhaps the most common political reaction to COVID-19 models-skepticism and outright criticism from Republican elites-had little effect on either support for using COVID-19 models to guide reopening policy in particular or support for science more generally. In no case did criticism of the models attributed to a Republican governor significantly reduce support for using models to guide policy decisions or adversely affect attitudes toward science more generally. Indeed, the only statistically significant effect was a backfire (27), that is updating in the direction opposite the elite cue. For Democrats, this cue was neither trusted nor costly. Republican criticism increased Democrats' support for relying on COVID-19 models by almost $15 \%$. Among Republicans, this cue from a trusted source decreased the percentage strongly supporting the use of COVID-19 models to guide policymaking by $6 \%$, but the difference was not statistically significant. Republican criticism also had no effect on general support for science. The mean science support index was actually higher for all respondents as well as for Democrats and Republicans individually in this treatment group than in the control; however, none of the differences in means were statistically significant.

By contrast, criticism attributed to a Democratic governor - a contra type signal - was more influential. Democratic elite criticism did not significantly reduce support for relying on COVID-19 models specifically. However, it did significantly erode support for science more generally. Among all subjects, the science support index was almost 0.15 standard deviations lower in this treatment group than in the control and this difference in means was statistically significant. As we would expect for a contra type signal, there is little evidence that this effect varied across partisan subgroups. For Democrats, these cues were both from a trusted co-partisan source and contra type, making them influential. For Republicans, although these cues were not from a trusted source, their contra type nature distinguished them from cheap talk, rendering them influential. The other plausibly contra type signal, Republican support for COVID-19 models, had little effect on either COVID-19 specific or general science attitudes. But Democratic elite support significantly increased general support for science among fellow Democrats, for whom a co-partisan was a trusted cue-giver.

Finally, the two bipartisan treatments necessarily involved one contra type cue and one cue that was not. We find modest evidence that bipartisan criticism affected attitudes. In the aggregate, this cue reduced strong support for using COVID-19 models to guide policy by $6 \%(\mathrm{p}=0.13$, two-tailed 
test) and among Republicans by $13 \%$ ( $\mathrm{p}<0.05$, two-tailed test). Bipartisan support did not have any significant effect on either dependent variable.

\section{Study 2: Partisan criticism experiment}

Survey experiments inevitably involve tradeoffs between internal and external validity. The preceding experiment used carefully controlled statements with minimal changes across treatments to maximize internal validity. However, it is also important to examine the effects of real-world rhetoric by prominent politicians on public attitudes. Accordingly, in a second survey, we embedded a new experiment that again varied the partisan affiliation of the cue-giver, but this time added external validity by specifying the name of the cue giver and using their actual words. This second experiment only examined the effect of elite criticism of models, given the limited influence of supportive cues in the preceding experiment and the intrinsic importance of whether elite criticism can undermine support for science, even when that was not necessarily the signaling elite's intent. We conducted the May 7, 2020 study on a sample of 1,008 Americans.

To make the examples concrete, we used actual statements from a Democrat, Governor Andrew Cuomo of New York, and from a Republican, Senator John Cornyn of Texas, that raised concerns about an over-reliance on models to inform policy decisions. Both sharply criticized the inaccuracy of model projections and suggested that the great underlying uncertainty rendered them inappropriate guides for policymakers. Appearing on CNN on April 15, 2020, Governor Cuomo suggested that "They come up with all these projections, we're going to do this in May, we're going to do this in June, we're going to do this in July. They have no idea. We have no idea where we're going to be. Let's find out where we are. Let's find out the facts and then we'll make a decision. Everyone has been wrong about everything for this entire duration. Right? 45 days. To now project 60 days forward and say, this is what I think we need to do - stop. Stop with the game." To be sure, the main point of Cuomo's remarks was not to question COVID-19 science or to deny its usefulness in guiding policy. Cuomo's argument was that policymakers should respond to the best available scientific data in real time and de-emphasize future projections, which have a high degree of uncertainty. Nevertheless, he was sharply critical of model projections and these criticisms may have unintended consequences on public opinion, particularly given that such criticism is contra type and therefore is likely to be perceived as credible.

Our second treatment used critical language from an April 10, 2020 tweet by Senator Cornyn: "After \#COVID-19 crisis passes, could we have a good faith discussion about the uses and abuses of 'modeling' to predict the future? Everything from public health, to economic... predictions. It isn't the scientific method, folks." While the language and critique are even sharper-such asymmetries are inevitable when working with actual rhetoric-the substance of the comment is similar. However, this cue is not contra type and therefore may be less influential on public attitudes.

Figure 2 illustrates the effects of each treatment on support for using COVID-19 models to guide reopening policy and on trust in and support for science more broadly. I-bars present $90 \%$ confidence intervals around each difference in means between the treatment and control group. The results offer significant evidence for the contra type hypothesis. Democratic Governor Andrew Cuomo's criticism that the models have been wrong throughout had both immediate and broader effects. Among all subjects, the Cuomo treatment significantly decreased support for using models to guide reopening policies by $13 \%$. Cuomo's criticism also decreased the general science support index by almost 0.15 standard deviations. Moreover, on both metrics we found little evidence of partisan differences in response to Cuomo's rhetoric. The Cuomo treatment significantly reduced support for COVID-19 models and support for science more broadly among Democrats and Republicans alike. By contrast, Cornyn's criticism, which is not contra type, had no effect on attitudes along either dimension in the aggregate or among any partisan group.

\section{Study 3: Point predictions, reversals, and ranges of un- certainty}

The preceding experiments examined the direct consequences of politicization when partisan politicians question the accuracy of COVID-19 models. A core feature of both criticisms is that point predictions both ignore uncertainty and invariably change over time, thereby risking reversals or updates that appear to undermine the original predictions. Such reversals risk undermining public confidence in science and its role in policy-making. An alternative communication strategy is to explicitly acknowledge the uncertainty inherent in model predictions. The acknowledged uncertainty cue could increase support for science-based policy-making and confidence in science more broadly, but more emphasis on uncertainty could also increase public skepticism about models' utility and undermine support.

To test among these possible responses, we conducted a third experiment in two waves between May 19 and June 2, 2020 that randomly assigned 1,771 respondents to one of three experimental conditions. The first offered the IHME point prediction from May 12, 2020 of 147,040 COVID-19 deaths by August, with no accompanying estimate of uncertainty. The second condition reported the same point estimate, but noted that this figure is "double the estimate produced by the model in April," a reversal of the original prediction. The third condition, the acknowledged 
uncertainty cue, offered a range rather than a point estimate, which is more accurate because small changes in assumptions and data upstream for a virus with exponential growth rates can lead to enormous downstream differences in projections. While emphasizing the enormous range in a model's estimates means that the eventual toll is less likely to be falsified, it could also backfire and undermine confidence because its nearly four-fold difference between lower and upper bound appears indeterminate. Our third treatment informed subjects that a prominent model "now predicts that COVID19 deaths will reach between 88,217 and 293,381 deaths by August." All three conditions were based on actual communication of COVID-19 fatality projections in the media (33).

Figure 3 presents the difference in means between the range and reversal treatments and the point estimate control group baseline. I-bars show $90 \%$ confidence intervals around each estimated treatment effect. Interestingly, neither treatment significantly affected public support for strongly relying on COVID-19 models to guide reopening decisions. Across all three experimental conditions, between $42 \%$ and $45 \%$ of subjects believed that policymakers should rely on epidemiological models "a great deal" when deciding when and how to reopen the economy.

However, both treatments highlighting uncertainty in model estimates decreased general public support for science. The reversal treatment, which noted that the May death estimate was double that predicted by the same model in April, decreased the science support index by approximately 0.1 standard deviations. Acknowledging the considerable uncertainty in model projections by presenting ranges rather than point estimates may insulate scientists from public reversals and their attendant costs. However, the range treatment itself also undermined popular trust in science and science-based policy-making. This treatment decreased the support for science index by more than 0.15 standard deviations. Such an approach to communicating scientific uncertainty may be more intellectually honest, but it nonetheless comes at a cost of eroding public confidence.

\section{Study 4: Catastrophizing consequences versus weapon- izing uncertainty}

Our fourth experiment examined more directly competing efforts to communicate uncertainty in ways that either demand urgent action or that caution against relying on scientific model projections to guide policy. This experiment provides the most direct test yet of the relative effects of communications that weaponize uncertainty to cast doubt on COVID-19 science versus those that ignore uncertainty and catastrophize the consequences that will inevitably follow from failing to heed the models.

On May 24-25, 2020, we employed a 2x2 experimental design-varying assignment to the weaponizing, catastrophizing, neither (control), or both treatments-on a sample of 1,001 Americans. Subjects randomly assigned to the control group read only the latest point prediction from a prominent model: "Because of relaxed social distancing, many prominent scientific models now predict that more than 130,000 Americans will die of COVID-19 by the end of June." Subjects in the weaponizing uncertainty group received the same point prediction, but were also told: "However, some officials note that the data on COVID-19 is imperfect, and the models have high levels of uncertainty and can produce misleading conclusions."

By contrast, after reading the point prediction language, subjects in the catastrophizing treatment received a warning about the dire and almost certain consequences of failing to follow the models: "Some officials argue that re-opening too quickly and ignoring the models' warning about increased deaths is 'an experiment in human sacrifice." The human sacrifice language was taken directly from prominent media coverage warning against early economic re-openings (24). Finally, those in the combined treatment received both arguments.

Figure 4 presents the difference in means between each of the three treatments and the control group baseline. I-bars show $90 \%$ confidence intervals around each estimated treatment effect. The weaponizing uncertainty treatment had no corrosive effect either on support for using COVID-19 models to guide reopening or on attitudes toward science more generally. In the previous experiment, highlighting major swings in actual model predictions over a short time did significantly reduce public support for and trust in science. However, in contrast to concrete reversals, the argument here emphasizing uncertainty and warning about potentially misleading conclusions had little impact in isolation.

Advocates of an aggressive response to stop the virus' spread have often pointed to dire model predictions and graphic warnings about the likely death toll to justify an extended lockdown. We found no evidence that such catastrophic cues, which make no mention of the uncertainty inherent in model estimates, backfired, at least in the short term. Instead, stark rhetoric about "human sacrifice" sharply increased support for relying heavily on models to guide reopening decisions by $21 \%$. It also increased the science support score by 0.1 standard deviation, but the effect was not statistically significant.

Finally, presenting subjects with both arguments - a call to heed the models to avoid a likely surge in human deaths and a cautionary counter warning of the considerable uncertainty in the models and the potential for error - suggests that the latter tempered but did not completely offset the effect of the former. Support for relying on COVID-19 models to inform policy was still $12 \%$ greater in this combined treatment than in the point estimate baseline group. The 
estimated effect of the combined treatment on support for science more generally was also smaller than in the catastrophizing treatment, though it too was statistically insignificant.

\section{Study 5: Weaponizing versus acknowledging and con- textualizing uncertainty in the scientific process}

The final experiment offers another angle on uncertainty in what scientists know and do not know about the virus and the contestation surrounding unsettled science. The pandemic has forced science to develop models and predictions at breakneck speed. Much of the science will ultimately be unreliable or debunked, with the best available research today being wrong tomorrow. Multiple studies with important policy consequences have ultimately been retracted, notably a Stanford study suggesting that the virus was less lethal than experts had acknowledged, which the conservative media used to argue that widespread lockdowns were unnecessary. The study was later discredited and the authors published a revised version that conceded greater degrees of uncertainty about the actual number of infections (34). Further, after months of recommending that healthy individuals not wear face masks, the CDC changed its guidance in early April in response to mounting evidence of asymptomatic transmission (35). These reversals and retractions of scientific findings with policy consequences highlight the considerable uncertainty in what we know and do not know about the virus and open the door for politicization by critics of sciencebased policies.

Our final experiment, conducted on a sample of 999 Americans on May 24-25, 2020 examines the efficacy of such critiques, as well as the extent to which they can be combated by a pair of justifications that seek not only to acknowledge but to explain and contextualize the uncertainty inherent in the scientific process. Subjects were randomly assigned to one of four groups. Those in the control group received no discussion of COVID-19 research. Those assigned to each of the three treatment conditions first read a basic prompt describing the accelerated pace of COVID-19 research: "As the coronavirus has spread across the globe, scientific research has raced to keep pace. Preliminary findings are now shared publicly before they have been reviewed by other scientists." Those in the uncertainty treatment also read a second prompt criticizing the retractions of studies and reversals in guidance that have occurred given the considerable uncertainty underlying early work on COVID-19, broadly consistent with an effort to indict the science because of its uncertainty: "Some officials warn that this speed has come at a cost. Several preliminary studies were flawed, and others offered competing conclusions. As a result, the scientific consensus has changed over time. In some cases, this has led to reversals in scientific guidance, for example over whether the general public should wear masks."

Subjects in the third and fourth treatments received the same initial prompt and critique as those in the uncertainty treatment. However, subjects in these groups also received arguments that acknowledged and contextualized the uncertainties in COVID-19 science. The first emphasized the immediacy of the pandemic and uses it to justify the accelerated pace of scientific research, even if there are inevitably tradeoffs. The second justification sought to explain that uncertainty is inherent in the scientific enterprise and that shifts in scientific consensus are part and parcel of the scientific process. Those in the speed justification were told that "other officials argue that such reversals are inevitable given the need to act quickly. Rapid sharing of information can help other researchers studying COVID-19. This improves our understanding of the best way to combat the virus." Those in the process justification were instead told that "other officials argue that such reversals are a key part of the scientific process. Scientists constantly update their conclusions based on new data. This improves our understanding of the best way to combat the virus."

Figure 5 presents the difference in means between each of the three treatments and the control group baseline. I-bars show $90 \%$ confidence intervals around each estimated treatment effect. None of the treatments had a significant effect on support for using scientific models to guide reopening decisions. The pattern of results is at least consistent with the criticism treatment reducing general support for science and the two justification treatments blunting that effect. However, none of the differences in means are statistically significant. The pace of COVID-19 research and the extent to which preliminary findings have entered the domain is unprecedented. However, at least in the early stages of the pandemic, we find little evidence that efforts to exploit the resulting uncertainty or defend against such weaponization had significant effects on Americans' policy preferences or confidence in science.

\section{The moderating role of scientific knowledge}

Decades of opinion research has shown that most of the public lacks basic factual knowledge about science and an understanding of the scientific method $(36,37)$. The deficit model, even if it has become something of a straw man in the public understanding of science literature, has a simple intuitive logic. This lack of understanding fuels skepticism toward science. While studies have plainly showed that the relationships in play are far more complex than the deficit model allows, empirical analyses continue to find strong correlations between science knowledge and attitudes, even after controlling for a host of other factors. As Sturgis and Allen note, "there is ample reason to consider it quite implausible that the well-informed and poorly informed citizen go about 
the business of making up their minds in the same way.(38)" Accordingly, we examine how scientific knowledge may moderate the effect of communications about scientific uncertainty on attitudes.

We explore two possibilities. First, subjects with greater scientific knowledge may be less swayed by efforts to politicize uncertainty in emerging science on the new coronavirus. Armed with greater scientific understanding, they may be better able to filter out extreme messaging and less responsive to efforts to weaponize uncertainty or catastrophize the consequences of failing to heed model projections. Alternately, it is possible that efforts to politicize uncertainty may be most effective among those with high science knowledge because they have greater ex ante faith in science's ability to guide policymaking. For example, emphasizing reversals in model predictions or scientific guidance raise questions about the utility of science in policymaking - questions that those with low levels of scientific knowledge may already possess. More scientifically literate subjects may better grasp arguments about the considerable uncertainty underlying science on a novel virus and connect them to questions of policy more broadly.

To examine the moderating role of science knowledge, we estimated regression models interacting each treatment with each subject's scientific knowledge, measured as the number of correct responses to a battery of eight true/false questions. We focus on uncertainty treatments from experiments 3 and 4 where at least one treatment had a statistically significant effect in the aggregate: that is we examine the effects of the reversal and range treatments on the science support index and of the weaponizing, catastrophizing, and combined treatments on support for the use of COVID-19 models in guiding reopening policy.

The top panels of Fig. 6 show that the effects of both the range and reversal treatments in experiment 3 were greatest among subjects with high levels of scientific knowledge. Indeed, among those with low levels of knowledge, the difference in predicted science support scores across treatment and control groups is statistically insignificant. However, as scientific knowledge increases the gap in predictions grows and science support becomes significantly lower in each treatment group than in the control. A floor effect may explain at least part of this divergence. Support for science is already very low among Americans with low levels of scientific knowledge. As a result, it simply does not have much further to fall in the reversal and range treatments. Alternately, scientifically knowledgeable subjects may have been better able to assess the implications of the reversal and range treatments and update their beliefs accordingly. The intensified negative effects of the reversal and range treatments on support for science among the most scientifically literate raises concerns, but it also suggests an opportunity: scientifically knowledgeable citizens are most equipped to understand more nuanced arguments acknowledging and contextualizing this inherent uncertainty. Although beyond the scope of our data and analysis, more sophisticated science communications may be able to blunt these adverse effects.

The bottom panels of Fig. 6 examine the moderating role of scientific knowledge on the effects of the weaponizing, catastrophizing, and combined treatments on support for using COVID-19 models to guide policy in experiment 4 . The weaponizing uncertainty treatment did not have a statistically significant effect in the aggregate, and the treatment effect did not vary with scientific knowledge. However, scientific knowledge significantly moderated the effects of the catastrophizing and combined treatments. The catastrophizing treatment - which explicitly downplayed uncertainty and offered dire warnings of the life and death consequences of failing to heed COVID-19 models - significantly increased support for using the models to guide policy. The effect was concentrated among subjects with low levels of scientific knowledge. At the bottom of the knowledge distribution, the effects are extreme, roughly quadrupling the predicted probability of supporting the policy use of COVID-19 models from the control the treatment. However, among scientifically knowledgeable subjects, the treatment had little or no effect. The combined treatment, while less influential than receiving the catastrophizing cue only, similarly had the greatest influence on subjects with low levels of scientific knowledge. If Americans with low levels of scientific literacy are also less attentive and politically engaged in science policy, then the long-term benefit of the boost in support for science produced by the catastrophizing argument observed in the aggregate may be limited.

\section{Discussion}

Scientific models reduce complex phenomena into simplified approximations that inform policymakers about the likelihood of future events. Just as without a weather forecast individuals do not know whether to bring an umbrella, without predictions for everything ranging from the economy to climate to contagion, policymakers cannot weigh tradeoffs between cost, benefit, and risk, nor allocate resources, nor offer guidance to citizens about how to ensure their well-being. Despite the value of models, they are necessarily imperfect, based on incomplete data, missing variables, and uncertainty about the relationship between cause, effect, and the feedback between the two.

Uncertainty raises questions about how political and media communications about an unsettled science of a lethal virus affect public opinion and support for science-based policy solutions. For elites skeptical of emerging science - be they political, media, or economic elites - uncertainty can be manipulated and weaponized because it offers ways to sow 
doubt, which Bolsen and Druckman show is done "by accentuating a finding's inherent uncertainty," which is "typically done not in an effort for scientific accuracy but rather in pursuit of a particular agenda.(39)" Highlighting and exploiting uncertainty has successfully undermined public beliefs in scientific claims and support for science-based policy in other contexts, such as climate change. Building on this work, our results examined whether similar arguments affect support for science-based policymaking in the early stages of a global pandemic unprecedented in the history of modern polling.

Our research examining the attitudes of more than 6,000 adult Americans over five different experiments suggests that the form of scientific communication-who invoked COVID19 models and how, as well as cues about uncertainty in the models and COVID-19 science more generally-affects both immediate support for the use of epidemiological models to guide reopening decisions as well as public attitudes toward science more generally, important proxies for willingness to heed key public health guidelines.

To date, most criticism of COVID-19 models and science more broadly has emanated from the political right. However, we find little evidence that criticism from Republicans changes Americans' willingness to use models to guide reopening decisions or how they view science. Most Americans appear to expect and therefore discount Republican rejection of scientific models because it conveys little new information. On the other hand, Republican support for COVID-19 science, which is a contra type signal, also had little effect. While the most prominent political criticism of the policy relevance of COVID-19 models came from the political right, Republican governors in Maryland, Massachusetts, and Ohio publicly embraced scientific guidance and the need to follow it. This split in Republican elite messaging may have made the Republican support cue in our experiment less surprising and influential. Democratic criticism, by contrast, does act negatively in the contra type manner hypothesized, eroding public trust because the public infers that the doubt cast on models is not ideologically motivated but rooted in an objective basis to doubt the science.

That the public appears to be more sensitive to the way Democrats discuss models than Republicans puts more onus upon Democrats to communicate the science carefully, especially the censure of models. Even criticism that focuses squarely on inaccurate model projections, such as Governor Cuomo's comments examined in experiment 2, can have the unintended consequence of undermining trust in science and support for science-based policy-making more broadly.

Turning from the cue giver to the cue given, we also find that while uncertainty is inherent in epidemiological models, acknowledging nuance and uncertainty is initially less persuasive than an alternative cue that emphasizes deterministic and fatalistic outcomes. On the other hand, scientific reversals in those predictions undermines public trust in science. Thus, while the more exaggerated narrative may produce short-term gains in trust, it may come at a longer-term cost when those prognostications are falsified.

Our results offer insights into whether contestation over uncertainty inherent in emerging COVID-19 science has spillover effects by eroding public trust in and support for science more broadly. While an extensive literature examines the impact of ideology (40), news consumption (41), and other correlates of trust in science, important questions remain about how the contextual features of politicized science communication affect attitudes toward science more generally. The COVID-19 pandemic has taken scientific debates that often appear abstract, unfold in relative obscurity behind journal paywalls, and, as in the case of climate change, involve longer time horizons than those salient to most citizens, and made these debates of immediate relevance and importance to millions across the globe. Our results suggest that the presentation of the scientific uncertainty in the media and how other actors seek to politicize it affects both immediate public support for using COVID-19 models to guide policymaking and public attitudes toward science more generally. The lasting implications of the latter could be particularly significant.

Our experiments considered COVID-19 model projections and reversals, but scholars might also consider the potential cost to public trust when multiple reversals aggregate. These scenarios might include different types of reversals and consider the erosion of trust when the CDC reverses guidance on masks and projected fatalities. On a related note, whether the effects of reversals vary by institution -for example, whether the public responds differently to reversals by the CDC versus WHO-should be considered. Researchers might also employ alternate experimental designs that permit within-subject analysis to evaluate the erosion of trust over time and whether such reductions persist. This approach could provide further insight into how fluctuating projections and the communications about these fluctuations and ranges affect public trust in science and in turn the likelihood that the public will follow government health guidelines.

Given the novelty of the COVID-19 virus, scientists will continue to accrue more data, identify missing variables, and learn more about the relationship between human behavior and disease transmission. Our results suggest that a more measured approach to scientific communication that seeks to explain and contextualize uncertainty inherent in the science is not just normatively appealing, but also perhaps strategic. It does pose some risks. Acknowledging the range in model predictions, instead of a more precise point prediction, reduced public trust in science, particularly among those with high levels of scientific knowledge predisposed to support the scientific enterprise. Endeavoring to explain inherent uncertainty also forgoes potential short-term increases in support 
for science-based policymaking produced by catastrophizing narratives that ignore the uncertainty underlying scientific projections. However, our results do suggest that when model projections prove wrong, it can erode public support for science. Thus, in the long term, acknowledging and contextualizing uncertainty may minimize public backlash should scientific projections and guidance change dramatically.

\section{Materials and Methods Sample characteristics}

Our research followed relevant ethical regulations. The Cornell University institutional review board approved all study protocols (Protocol ID 2004009569). Our five survey experiments were embedded on four online surveys conducted in May-June 2020. These experiments allowed us to test our hypotheses that contra type elite cues about COVID-19 models will be more influential in shaping public attitudes toward science, and to test the relative influence of science communications that engage different aspects of uncertainty inherent in COVID-19 research.

To calculate minimum sample sizes for each experiment, we conducted a power analysis. To detect treatment effects of 0.25 standard deviations with Type I error rate $\alpha=0.05$ and with a power of 0.80 , requires 253 subjects per experimental cell. In our first experiment, 2,038 subjects were randomly assigned to seven experimental conditions, yielding sample sizes per experimental cell ranging from 288 to 295 . In our second experiment, 1,008 subjects were randomly assigned to one of three experimental conditions, yielding sample sizes per experimental cell ranging from 331 to 341 . In our third experiment, 1,771 subjects were randomly assigned to one of four experimental conditions, yielding sample sizes per experimental cell ranging from 248 to 252 . In our fourth experiment, 1,001 subjects were randomly assigned to one of four experimental conditions, yielding sample sizes per experimental cell ranging from 248 to 252 . Finally, our fifth experiment randomly assigned 999 subjects to four experimental conditions, yielding sample sizes per experimental cell ranging from 249 to 251.

All of our survey subjects were recruited via the Lucid platform. Lucid employs quota sampling to produce samples matched to the US population on age, gender, ethnicity, and geographic region (42). The demographic composition of our samples and comparisons to those of prominent social science surveys and U.S. Census American Community Survey statistics are provided in Table S1.

At the beginning of each survey, subjects read a consent form and provided informed consent. This consent form read, in part: "We will ask you to read and reply to a few brief questions. After these questions, you will be asked a series of background questions. These will include questions about your age, gender, race, income, and education. At no point will you be asked any question which could personally identify you. Thus, we assure you that your responses will be anonymous and confidential." Subjects were also told that their "participation in this research is voluntary" and that they "have the right to withdraw at any point during the study, for any reason and the data you have submitted to that point will be destroyed and not stored for use."

\section{Sources for experimental design features}

To examine the effects of the cue-giver on a COVID-19 cue's perceived credibility and influence on public opinion, experiment 1 employed the same two statements either supporting or criticizing the use of models to guide economic reopening decisions. The general statements were based on media reporting of political reactions to the epidemiological models. The experimental manipulations then varied whether the source of the signaling elite was a Democratic governor, a Republican governor, or a pair of governors, one Democrat and one Republican.

Experiment 2 examined the effect of actual rhetoric by prominent politicians on both sides of the aisle about the policy utility of COVID-19 models. The quotation from Governor Andrew Cuomo (D-NY) was taken from a CNN interview on April 15, 2020. The quotation from Senator John Cornyn (RTX) was taken from a tweet issued by the Senator on April 10, 2020.

Experiment 3 examined the effects of how epidemiological model projections are presented - either as a point prediction; a point prediction that notes the considerable reversal from an earlier estimate; or as a range, rather than a point projection - on public attitudes toward science. The point projection used in the baseline condition was the point estimate from the IHME model, the model most frequently used by the White House, as of May 12, 2020. The reversal notes that the current projection is more than double the estimate from the same model in April (i.e., from the April 10, 2020 report). The final treatment instead gave an estimated range of deaths, rather than a point prediction. The estimate range $(88,217$ to 293,381$)$ for the range treatment was taken from the Gu model as reported in Stat (33). This was moderately wider than that produced by the IHME model (113,182 to 226,971). Experiment 3 was embedded on two survey waves, the first fielded on May $19(\mathrm{n}=1020)$ and the second on June $2(\mathrm{n}=751)$. The difference in means and regression analyses pool data from both waves. However, to ensure that there were no systematic differences across waves, we re-estimated the models in Table S7 with interactions between each treatment and a dummy variable identifying subjects in the second survey wave. In each case, the coefficient on the interaction is statistically insignificant. Replicating the difference in means analysis in Fig. 3 with only data from the first wave yields substantively similar results. Neither treatment 
had a statistically significant effect on support for using COVID-19 models to guide reopening policy. Both the reversal and range treatments decreased the science support score by more than 0.1 standard deviations; however, with the smaller sample size in just the first survey wave, the former was not statistically significant ( $p<0.10$, two-tailed test).

Experiment 4 examined the effect of the weaponizing uncertainty and catastrophizing consequences arguments on support for science. The prompt across the treatment and control groups states that "because of relaxed social distancing, many prominent scientific models now predict that more than 130,000 Americans will die of COVID-19 by the end of June." This figure is taken from the May 4, 2020 IHME update, which predicted 134,475 US deaths through August.

Finally, experiment 5 examined the effect of competing arguments that either criticized the considerable uncertainty inherent in nascent COVID-19 science for producing reversals in the scientific consensus and public health guidance, or that explained the inevitability of uncertainty in the current context and justified the continued policy relevance of COVID-19 research. The substance and language of our treatments were based on the media debate playing out in the public sphere (34).

\section{Dependent variables}

All five experiments assessed the effect of science communication treatments on two dependent variables. The first question explicitly measured public support for using epidemiological models of COVID-19's spread to guide policy decisions on economic reopening. Subjects were asked: How much should policymakers rely on scientific models that project the likely spread of COVID-19 when deciding when and how to reopen the economy? Subjects answered on a fourpoint Likert scale ranging from "not at all" to "a great deal." We then created a binary dependent variable coded 1 if subjects responded "a great deal" and 0 if they selected another option. Across our surveys, "a great deal" was the modal answer with roughly $40 \%$ support.

The second dependent variable is an additive index of general support for science constructed from three questions commonly asked in past research on public attitudes toward science. The first question measured support for sciencebased policy more generally (29). Subjects were asked, "Which of these statements comes closer to your own view, even if neither is exactly right?" Subjects then chose between "scientists should take an active role in public policy debates about issues related to science and technology" or "scientists should focus on establishing sound scientific facts and stay out of policy debates." From this, we created a variable coded 1 for those who said scientists should take an active role in policy debates, and 0 for those who said scientists should stay out of policy debates. The second question, taken from the
National Science Foundation's Science and Engineering Indicators (30), asked, "How much confidence, if any, do you have in scientists to act in the best interests of the public?" Subjects answered on a four-point Likert scale ranging from "no confidence at all" to "a great deal." From this we created a binary variable coded 1 for subjects who expressed a great deal of confidence in science and 0 for those who did not. The final question (31) again asked subjects to choose which statement best reflects their views: "scientists make judgments based solely on the facts" or "scientists' judgments are just as likely to be biased as other people's." From this we created a variable coded 1 for those who chose the latter and 0 for those who chose the former. The additive science support index ranged from 0 to 3 . Across the 6,817 combined subjects in our five experiments, it averaged 1.65 with a standard deviation of 1.03 .

\section{Statistical analysis}

In each experiment, subjects were randomly assigned to one of the experimental conditions and then asked the four questions described above. We employ and report two methods for assessing the statistical significance of treatment effects. First, randomization tests showed little evidence of systematic demographic imbalances across experimental conditions in each survey (see Tables S2-S4). Accordingly, Figs. 1-5 plot the change in support for using COVID-19 models to guide reopening decisions (top panels) and the change in the general science support score (bottom panels) between each treatment condition and the corresponding control or baseline condition. I-bars present $90 \%$ confidence intervals around each difference in means. When the I-bars do not include the origin, the difference in means between the treatment and the control was statistically significant, $\mathrm{p}<0.10$, two-tailed test, in an independent samples $t$ test. This means that for any difference in means where the I-bar does not include the origin, there is less than a $5 \%$ chance of observing an effect this strong or stronger in our experiment when the true relationship is null or in the opposite direction. Thus, $90 \%$ confidence intervals are appropriate given the strong directional expectations for our treatments. Finally, while our experiments were powered to detect aggregate effects as described above, the sample sizes for the partisan subgroup analysis are necessarily smaller. Given our strong directional expectations in the partisan subgroup analyses, $90 \%$ confidence intervals are appropriate.

Alternately, we estimated two sets of regressions for each dependent variable in each experiment (Tables S5-S9). Logistic regressions were used to model strong support for using COVID-19 models to guide reopening decisions and OLS regressions to model the general science support score. The independent variables of interest are a series of indicator variables identifying assignment to each treatment condition. In 
each case, the omitted category is the control or baseline (i.e., the point estimate in experiment 3) condition. The first set of models include only the experimental indicator variables. As a robustness check, Table S10 estimates ordered logit models with this specification for each experiment using the full four-point likert scale version of the variable measuring support for using COVID-19 models to guide reopening decisions. The second set of models also control for each partisan subject's partisan affiliation (i.e., indicator variables for Democrats and Republicans); educational attainment; age; gender; race/ethnicity (i.e., indicator variables for blacks and Latinos); and an eight-point measure of science knowledge, which is an additive index of the number of correct responses to eight scientific factual knowledge questions derived from the National Science Foundation's Science and Engineering Indicators (30). For each of the science knowledge questions, subjects could answer that the statement was true, false, or that they were unsure.

Finally, in each experiment a subject's level of factual scientific knowledge was a strong and statistically significant predictor of support for using COVID-19 models to guide policy and the general science support score. To examine whether scientific knowledge also moderated statistically significant treatment effects we estimated a final pair of models (the final columns of Tables S7 and S8). These models interacted each treatment indicator variable with the variable measuring subjects' scientific knowledge. To ease the substantive interpretation of the interaction effects, Fig. 6 graphically presents the effects of each treatment at different levels of scientific knowledge.

\section{REFERENCES AND NOTES}

1. N. Ferguson, D. Laydon, G. Nedjati-Gilani, N. Imai, K. Ainslie, M. Baguelin, S. Bhatia, A. Boonyasiri, Z. Cucunubá, G. Cuomo-Dannenburg, A. Dighe, Report 9 - Impact of non-pharmaceutical interventions (NPIs) to reduce COVID-19 mortality and healthcare demand | Faculty of Medicine | Imperial College London. Imp. Coll. COVID Response Team (2020), (available at https://dsprdpub.cc.ic.ac.uk:8443/handle/10044/1/77482).

2. S. Begley, Influential COVID-19 model uses flawed methods and shouldn't guide U.S. policies, critics say. Stat 17 April (2020). 10.1101/2020.03.28.20046177V2

3. D. Siders, M. Ward, A fight over data infiltrates Trumpworld's response to coronavirus. Politico 10 April (2020).

4. J. N. Druckman, The crisis of politicization within and beyond science. Nat. Hum. Behav. 1, 615-617 (2017). doi:10.1038/s41562-017-0183-5 Medline

5. L. Uusitalo, A. Lehikoinen, I. Helle, K. Myrberg, An overview of methods to evaluate uncertainty of deterministic models in decision support. Environ. Model. Softw. 63, 24-31 (2015). doi:10.1016/i.envsoft.2014.09.017

6. I. Holmdahl, C. Buckee, Wrong but Useful - What Covid-19 Epidemiologic Models Can and Cannot Tell Us. N. Engl. J. Med. 383, 303-305 (2020). doi:10.1056/NEJMp2016822 Medline

7. R. Marchant, N. I. Samia, O. Rosen, M. A. Tanner, S. Cripps, Learning as we go: An examination of the statistical accuracy of COVID-19 daily death count predictions. arXiv:2004.04734 (2020), doi:10.1101/2020.04.11.20062257.

8. M. Wadman, How does coronavirus kill? Clinicians trace a ferocious rampage through the body, from brain to toes. Science (2020). doi:10.1126/science.abc3208

9. N. Oreskes, E. M. Conway, Merchants of Doubt: How a Handful of Scientists Obscured the Truth on Issues from Tobacco Smoke to Global Warming
(Bloomsbury Press, New York, 2010).

10. T. Bolsen, J. N. Druckman, F. L. Cook, How frames can undermine support for scientific adaptations: Politicization and the status-quo bias. Public Opin. Q. 78, 1-26 (2014). doi:10.1093/pog/nft044

11. J. Green, J. Edgerton, D. Naftel, K. Shoub, S. J. Cranmer, Elusive consensus: Polarization in elite communication on the COVID-19 pandemic. Sci. Adv. 6, eabc2717 (2020). doi:10.1126/sciadv.abc2717

12. B. Swire, A. J. Berinsky, S. Lewandowsky, U. K. H. Ecker, Processing political misinformation: Comprehending the Trump phenomenon. R. Soc. Open Sci. 4, 160802 (2017). doi:10.1098/rsos.160802 Medline

13. A. Lupia, Communicating science in politicized environments. Proc. Natl. Acad. Sci. U.S.A. 110 (Suppl 3), 14048-14054 (2013). doi:10.1073/pnas.1212726110 Medline

14. R. L. Calvert, The value of biased information: A rational choice model of political advice. J. Polit. 47, 530-555 (1985). doi:10.2307/2130895

15. R. Slothuus, Assessing the influence of political parties on public opinion: The challenge from pretreatment effects. Polit. Commun. 33, 302-327 (2016). doi:10.1080/10584609.2015.1052892

16. T. Bolsen, J. N. Druckman, Do partisanship and politicization undermine the impact of a scientific consensus message about climate change? Group Process. Intergroup Relat. 21, 389-402 (2018). doi:10.1177/1368430217737855

17. M. C. Nisbet, D. A. Scheufele, What's next for science communication? Promising directions and lingering distractions. Am. J. Bot. 96, 1767-1778 (2009). doi:10.3732/ajb.0900041 Medline

18. J. Greenberg, G. Knight, E. Westersund, Spinning climate change: Corporate and NGO public relations strategies in Canada and the United States. Int. Commun. Gaz. 73, 65-82 (2011). doi:10.1177/1748048510386742

19. E. U. Weber, P. C. Stern, Public understanding of climate change in the United States. Am. Psychol. 66, 315-328 (2011). doi:10.1037/a0023253 Medline

20. S. Lewandowsky, G. E. Gignac, S. Vaughan, The pivotal role of perceived scientific consensus in acceptance of science. Nat. Clim. Chang. 3, 399-404 (2013). doi:10.1038/nclimate1720

21. A. M. McCright, R. E. Dunlap, C. Xiao, Perceived scientific agreement and support for government action on climate change in the USA. Clim. Change 119, 511-518 (2013). doi:10.1007/s10584-013-0704-9

22. C. R. Foust, W. O'Shannon Murphy, Revealing and reframing apocalyptic tragedy in global warming discourse. Environ. Commun. 3, 151-167 (2009). doi:10.1080/17524030902916624

23. M. F. Dahlstrom, Using narratives and storytelling to communicate science with nonexpert audiences. Proc. Natl. Acad. Sci. U.S.A. 111 (Suppl 4), 13614-13620 (2014). doi:10.1073/pnas.1320645111 Medline

24. A. Mull, "Georgia's experiment in human sacrifice." The Atlantic, 29 April (2020).

25. E. Vaughn, Nate Silver points out the flaws in media reporting of COVID-19 data. Red State (2020).

26. Y. Katz, Against storytelling of scientific results. Nat. Methods 10, 1045 (2013) doi:10.1038/nmeth.2699 Medline

27. P. S. Hart, E. C. Nisbet, Boomerang effects in science communication: How motivated reasoning and identity cues amplify opinion polarization about climate mitigation policies. Communic. Res. 39, 701-723 (2012). doi:10.1177/0093650211416646

28. B. Nyhan, J. Reifler, P. A. Ubel, The hazards of correcting myths about health care reform. Med. Care 51, 127-132 (2013). doi:10.1097/MLR.0b013e318279486b Medline

29. A. D. Ross, R. Struminger, J. Winking, K. R. Wedemeyer-Strombel, Science as a public good: Findings from a survey of March for Science participants. Sci. Commun. 40, 228-245 (2018). doi:10.1177/1075547018758076

30. National Science Board, "Science and Engineering Indicators 2016" (Arlington, VA, 2016)

31. B. Kennedy, C. Funk, Democrats and Republicans differ over role and value of scientists in policy debates. Pew Res. Cent. (2019).

32. G. Tsipursky, (Dis)Trust in science. Psychol. Today (2018).

33. S. Begley, H. Empinado, How high will it go? Stat 30 April (2020).

34. A. Bajak, J. Howe, A Study Said Covid Wasn't that Deadly. The Right Seized It. New York Times (2020).

35. C. Rothe, M. Schunk, P. Sothmann, G. Bretzel, G. Froeschl, C. Wallrauch, T. 
Zimmer, V. Thiel, C. Janke, W. Guggemos, M. Seilmaier, C. Drosten, P. Vollmar, K. Zwirglmaier, S. Zange, R. Wölfel, M. Hoelscher, Transmission of 2019-NCOV infection from an asymptomatic contact in Germany. N. Engl. J. Med. 382, 970 971 (2020). doi:10.1056/NEJMc2001468 Medline

36. J. D. Miller, The measurement of civic scientific literacy. Public Underst. Sci. 7. 203-223 (1998). doi:10.1088/0963-6625/7/3/001

37. G. Evans, J. Durant, The relationship between knowledge and attitudes in the public understanding of science in Britain. Public Underst. Sci. 4, 57-74 (1995). doi:10.1088/0963-6625/4/1/004

38. P. Sturgis, N. Allum, Science in society: re-evaluating the deficit model of public attitudes. Public Underst. Sci. 13, 55-74 (2004). doi:10.1177/0963662504042690

39. T. Bolsen, J. N. Druckman, Counteracting the politicization of science. J. Commun. 65, 745-769 (2015). doi:10.1111/icom.12171

40. G. Gauchat, Politicization of science in the public sphere: A study of public trust in the United States, 1974 to 2010. Am. Sociol. Rev. 77, 167-187 (2012). doi:10.1177/0003122412438225

41. J. D. Hmielowski, L. Feldman, T. A. Myers, A. Leiserowitz, E. Maibach, An attack on science? Media use, trust in scientists, and perceptions of global warming. Public Underst. Sci. 23, 866-883 (2014). doi:10.1177/0963662513480091 Medline

42. A. Coppock, O. A. McClellan, Validating the demographic, political, psychological, and experimental results obtained from a new source of online survey respondents. Res. Polit. 6, (2019). doi:10.1177/2053168018822174

\section{ACKNOWLEDGMENTS}

This study has been approved by the Cornell University Institutional Review Board (Protocol ID 2004009569). Funding: We thank the Atkinson Center for Sustainability at Cornell University for financial support. Author Contributions: Both authors S.E. Kreps and D. L. Kriner contributed equally to the research design and implementation as well as to the writing of the paper. Competing Interests: Both authors declare that they have no competing interests. Data Availability: All data files and statistical code to produce the tables and figures reported in the manuscript will be published on the Harvard Dataverse upon acceptance for publication at: https://doi.org/10.7910/DVN/NJOJWP.

\section{SUPPLEMENTARY MATERIALS}

advances.sciencemag.org/cgi/content/full/sciadv.abd4563/DC1

Submitted 22 June 2020

Accepted 2 September 2020

Published First Release 25 September 2020

10.1126/sciadv.abd4563 
Strongly Support Use of Covid-19 Models

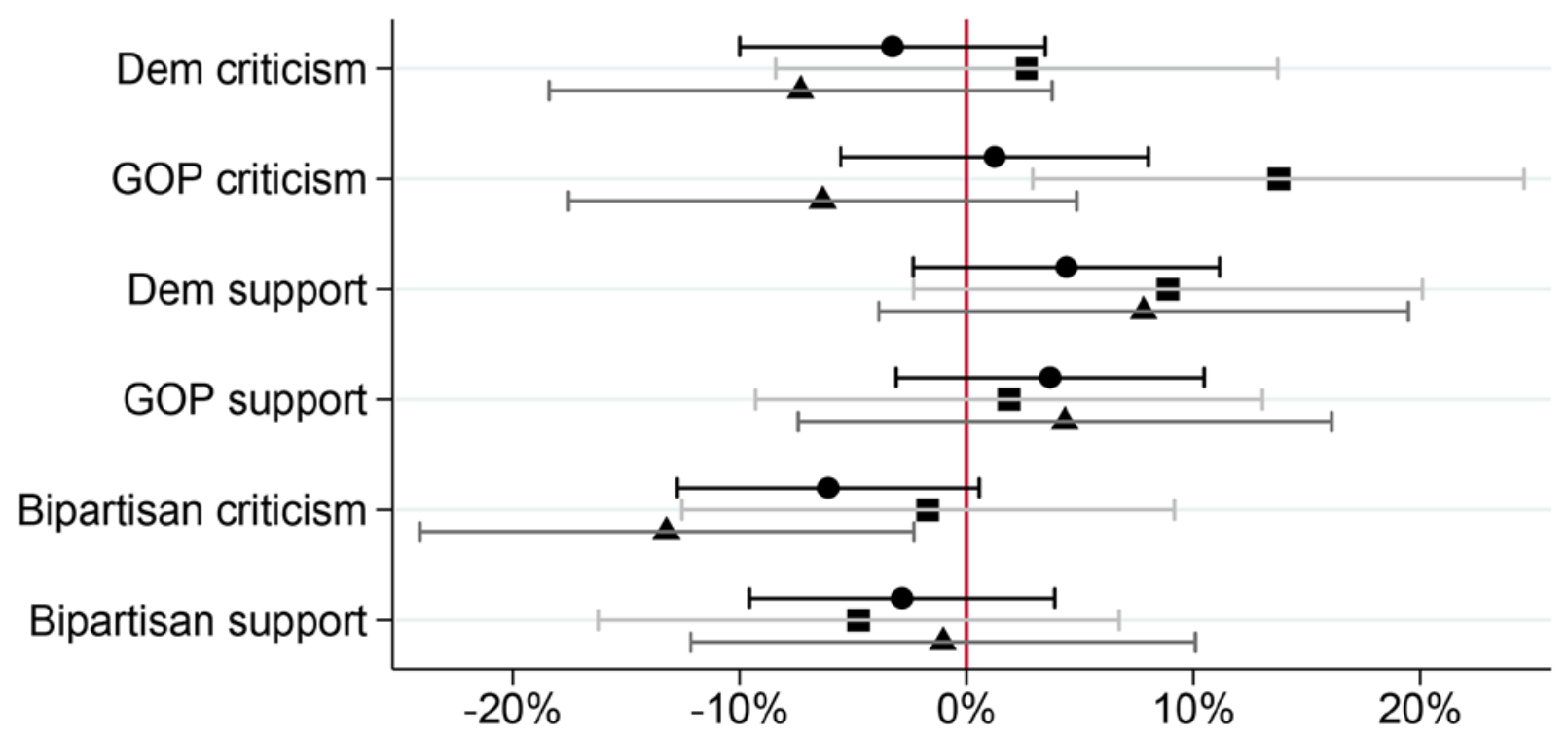

Change in Support

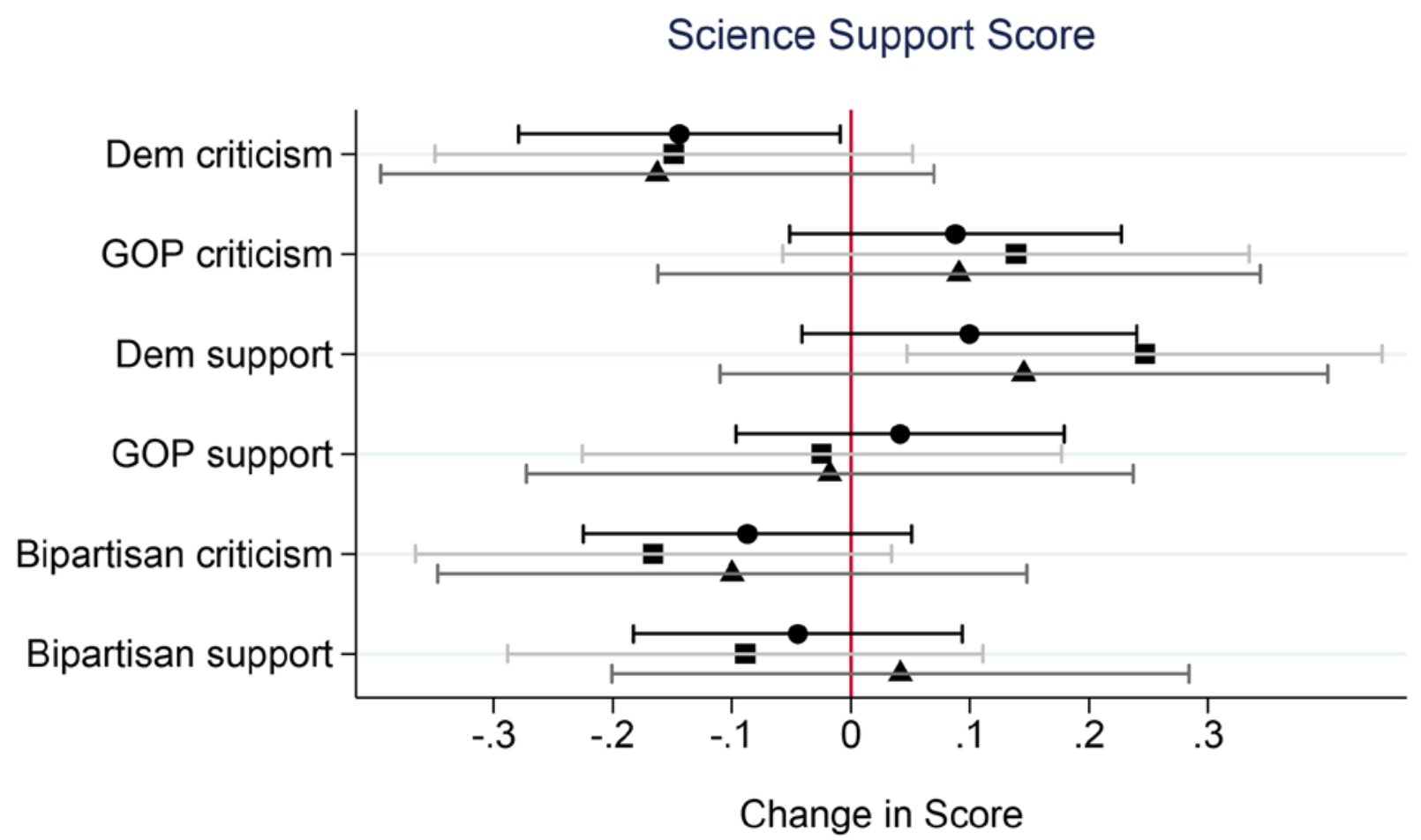
- All
- Democrats
- Republicans 
Fig. 1. Effects of partisan elite cues on support for models and general attitudes toward science. I-bars present $90 \%$ confidence intervals around each difference in means from the control group. 


\section{Strongly Support Use of Covid-19 Models}
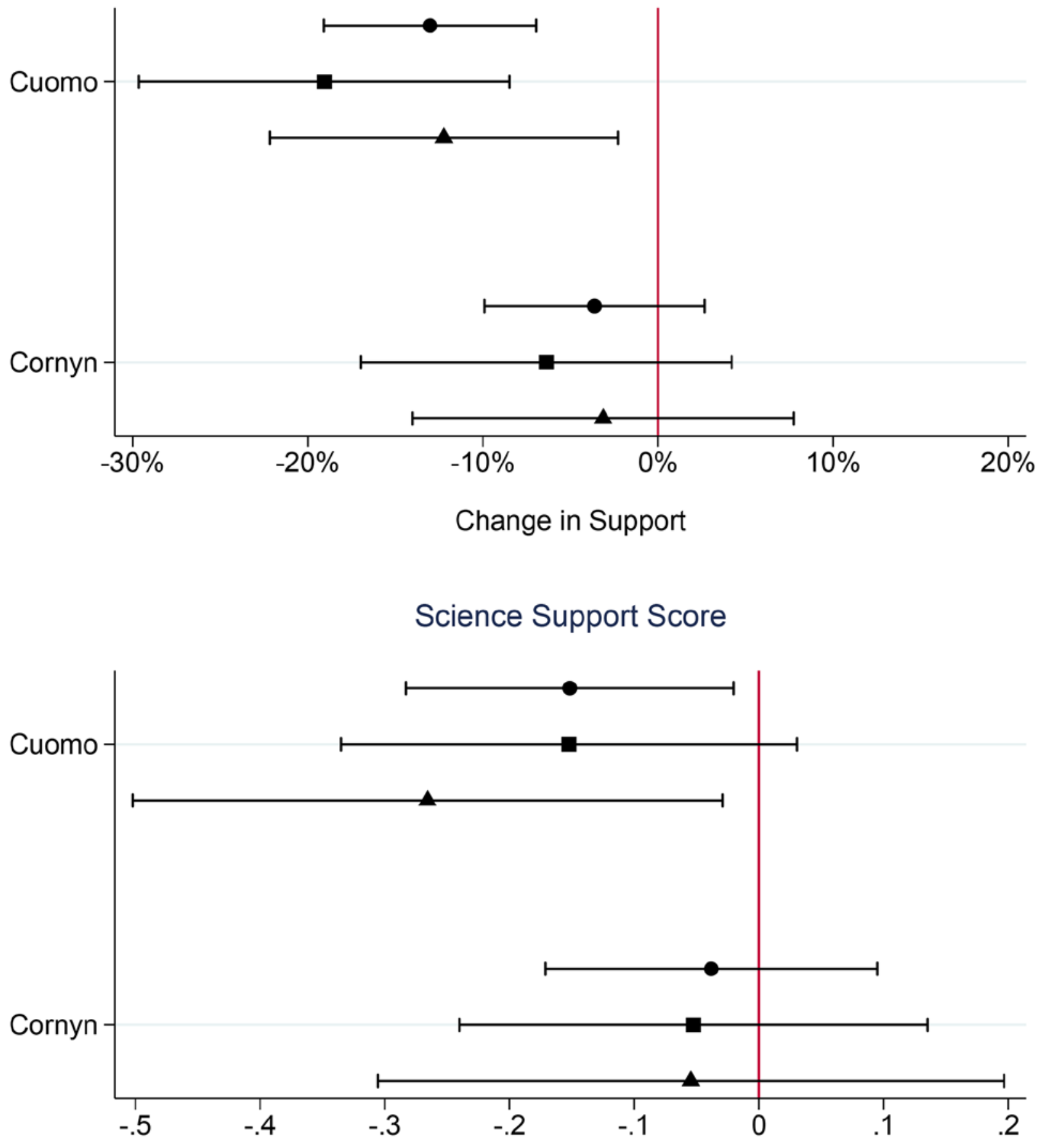

Change in Score

- All $\quad$ Democrats $\Delta$ Republicans


Fig. 2. Effects of elite criticism by party. I-bars present $90 \%$ confidence intervals around each difference in means from the control group. 


\section{Strongly Support Use of Covid-19 Models}

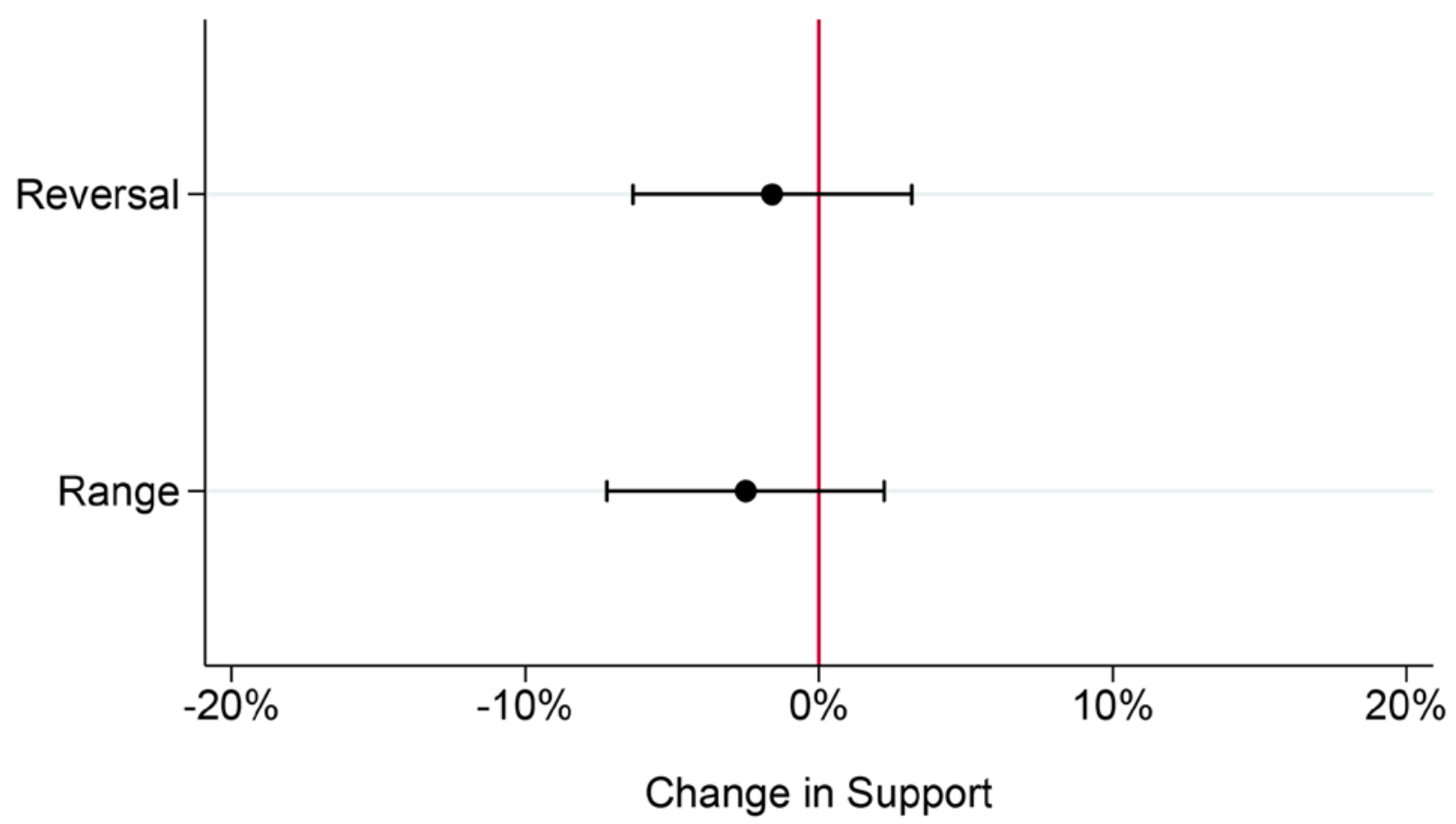

General Science Support Score

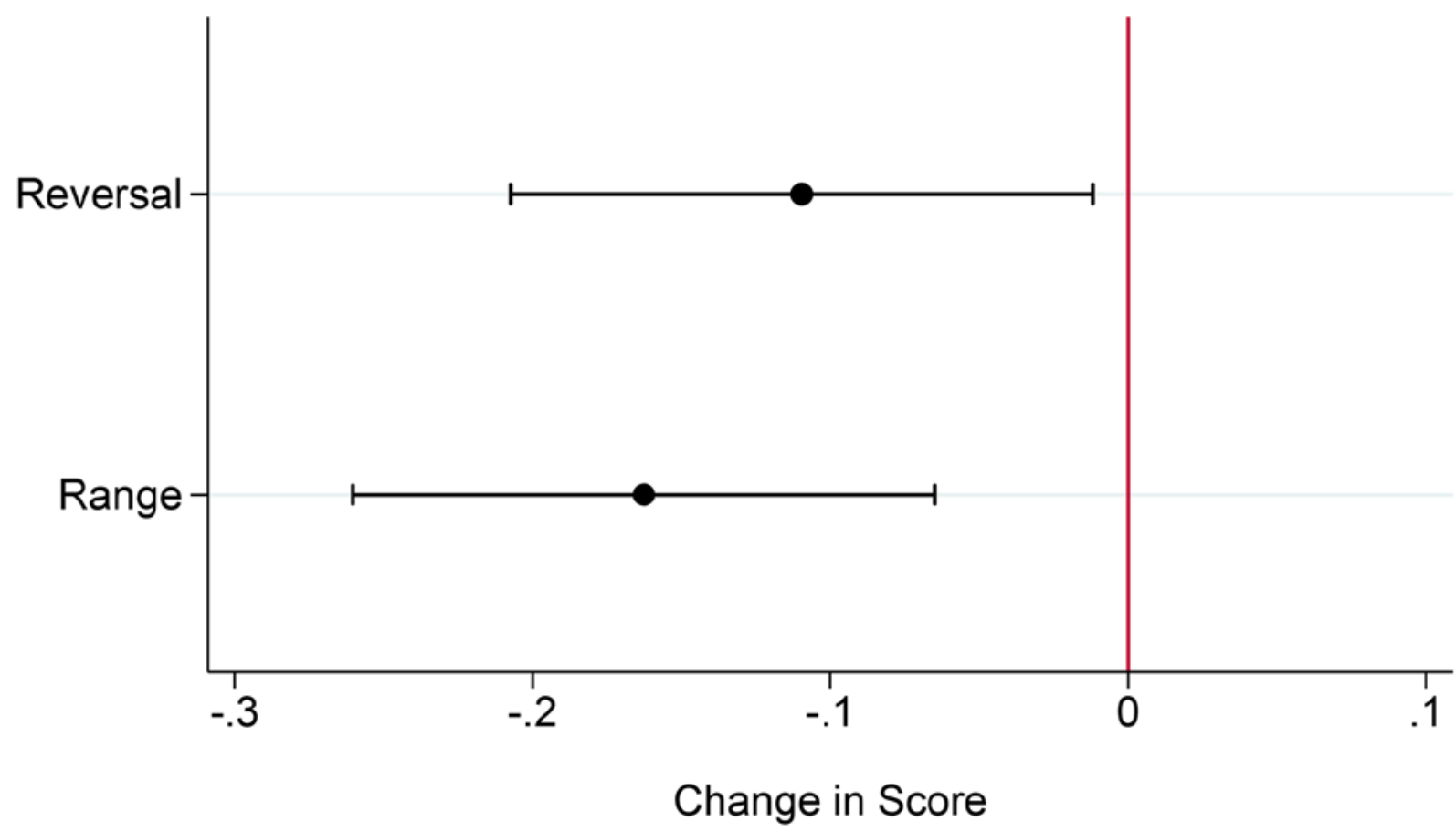


Fig. 3. Effects of prediction reversals and range. I-bars present $90 \%$ confidence intervals around each difference in means from the point estimate for the control group. 


\section{Strongly Support Use of Covid-19 Models}

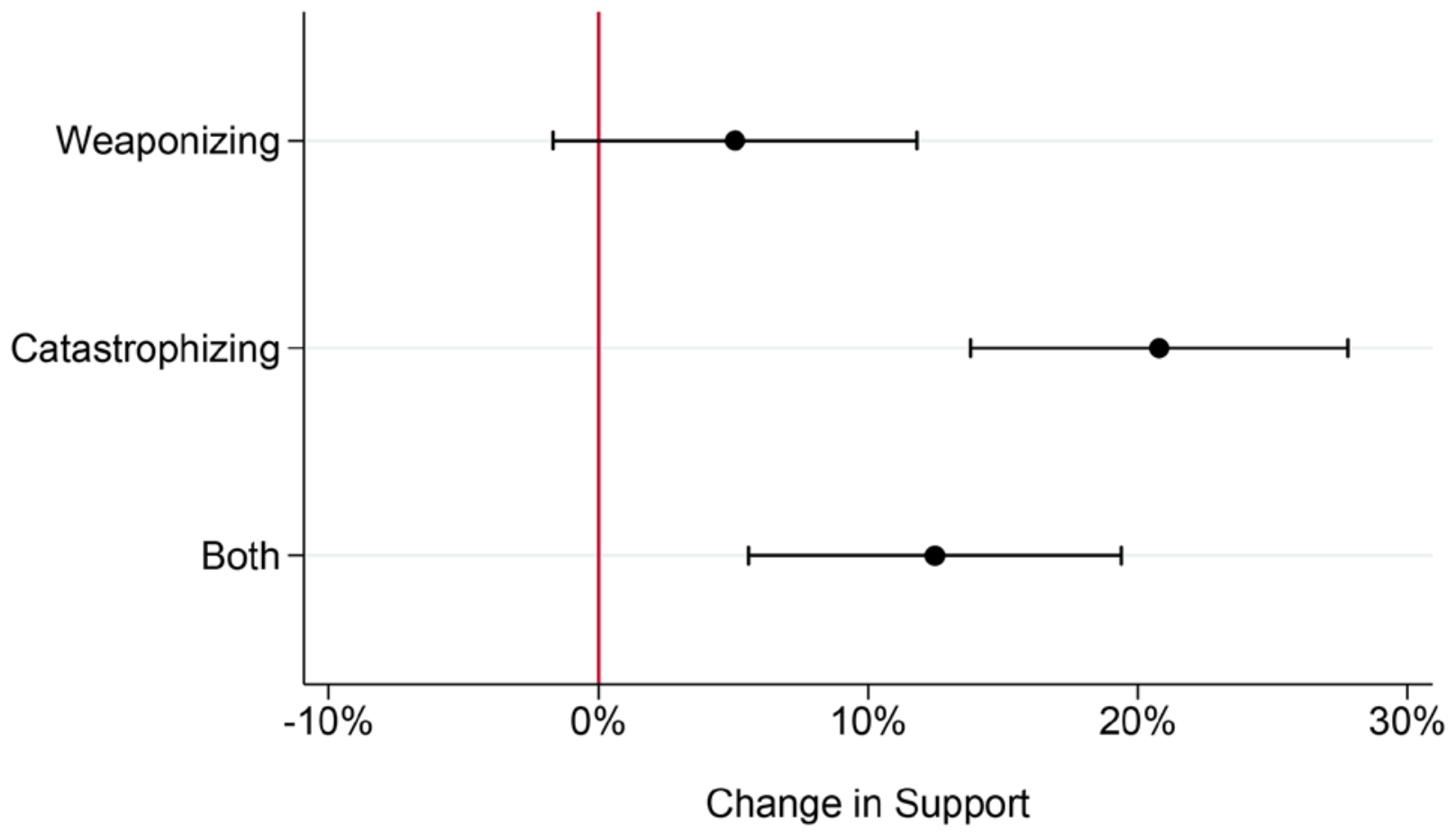

General Science Support Score

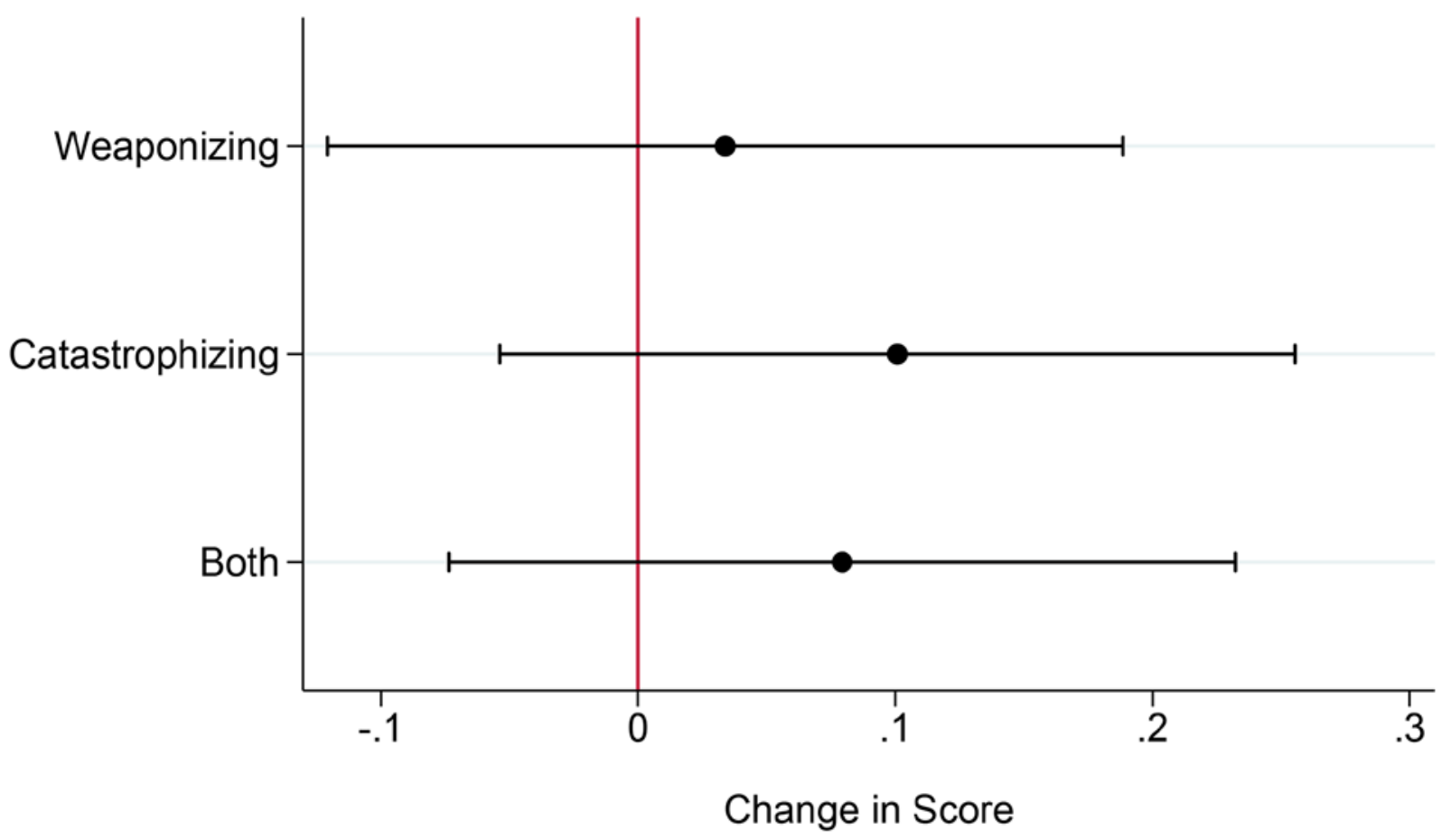


Fig. 4. Effects of weaponizing uncertainty versus catastrophizing consequences. I-bars present $90 \%$ confidence intervals around each difference in means from the control group. 


\section{Strongly Support Use of Covid-19 Models}

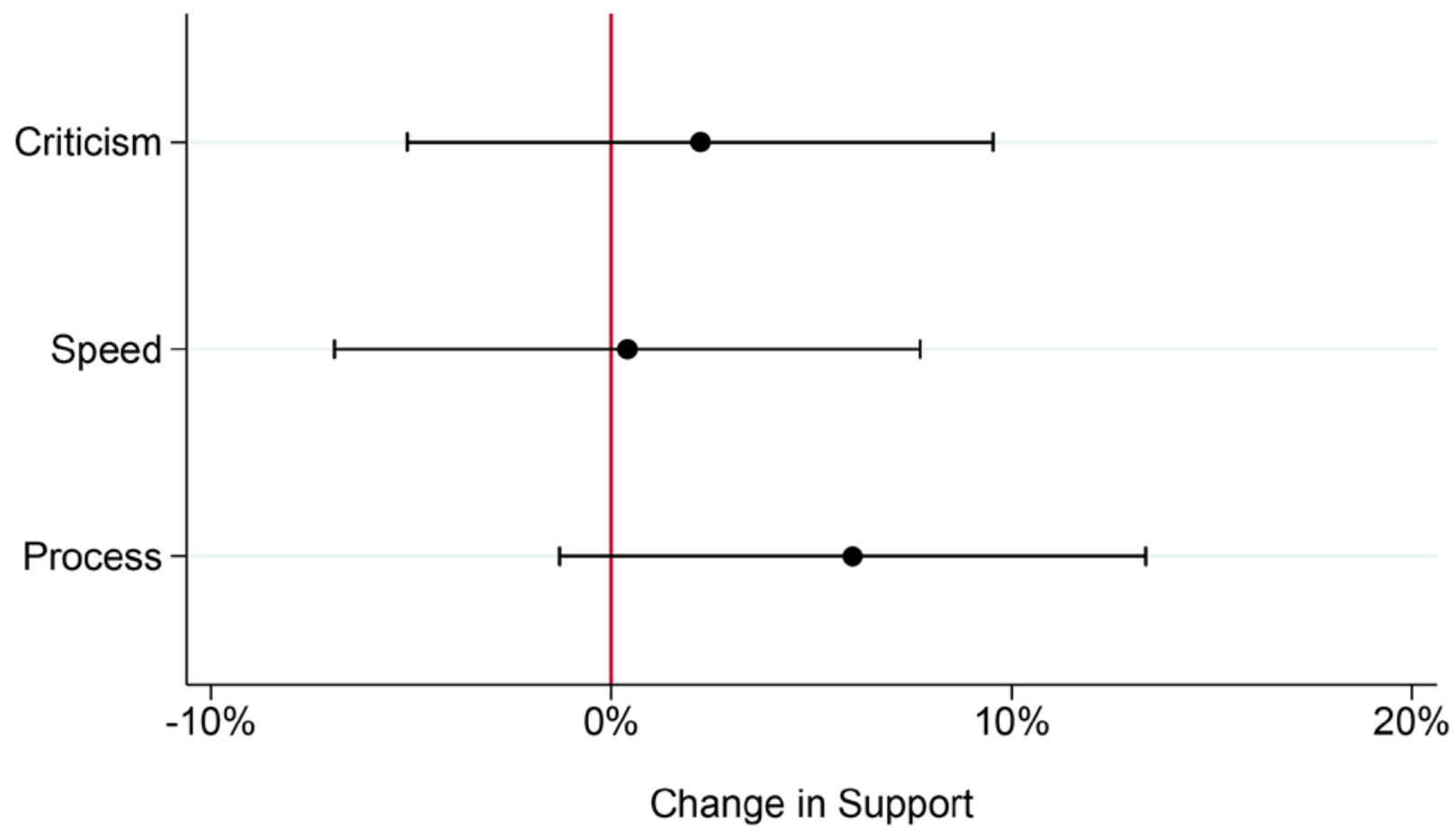

General Science Support Score

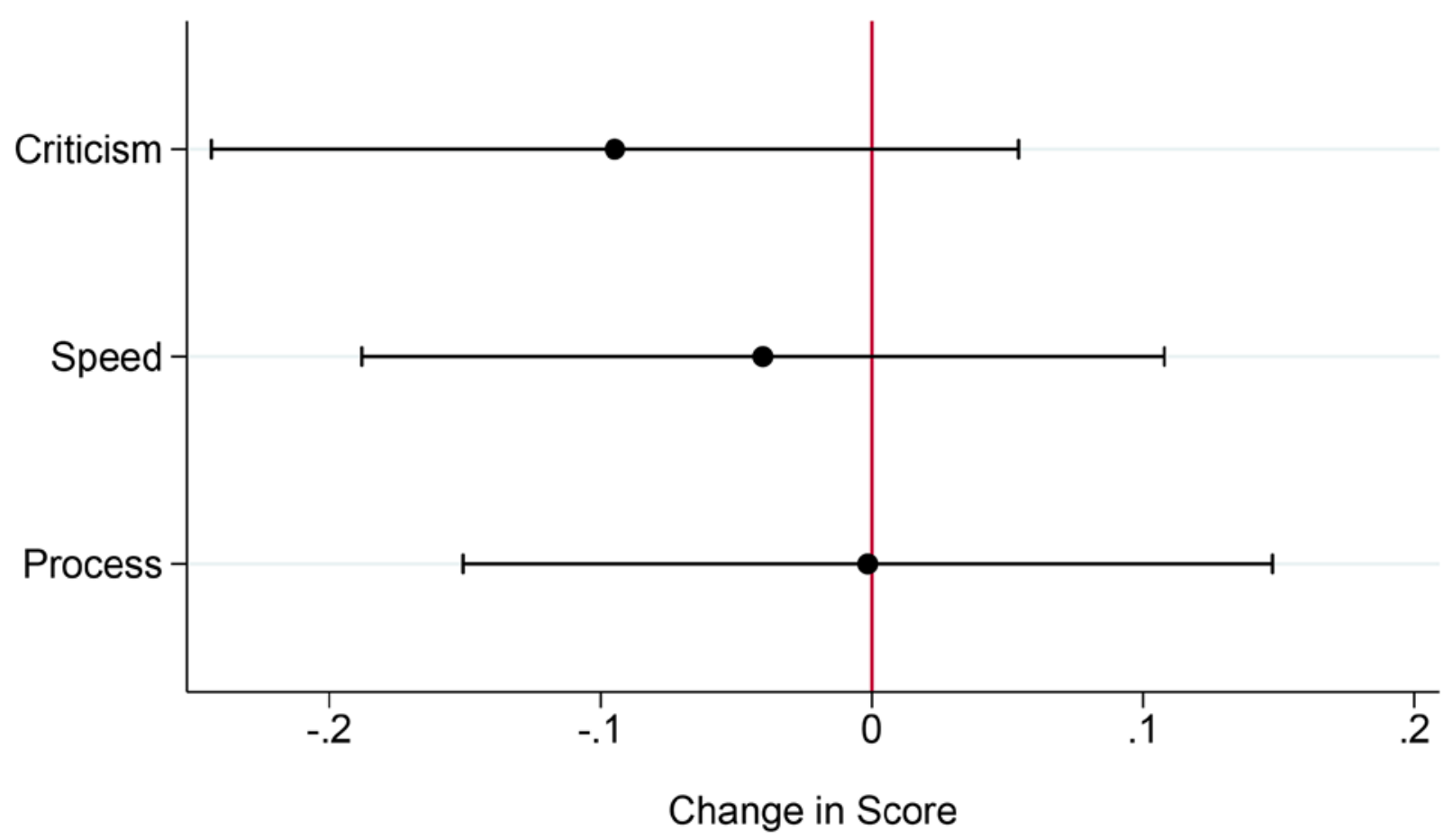


Fig. 5. Effects of criticisms about uncertainty in COVID-19 science versus justifications. I-bars present $90 \%$ confidence intervals around each difference in means from the control group. 

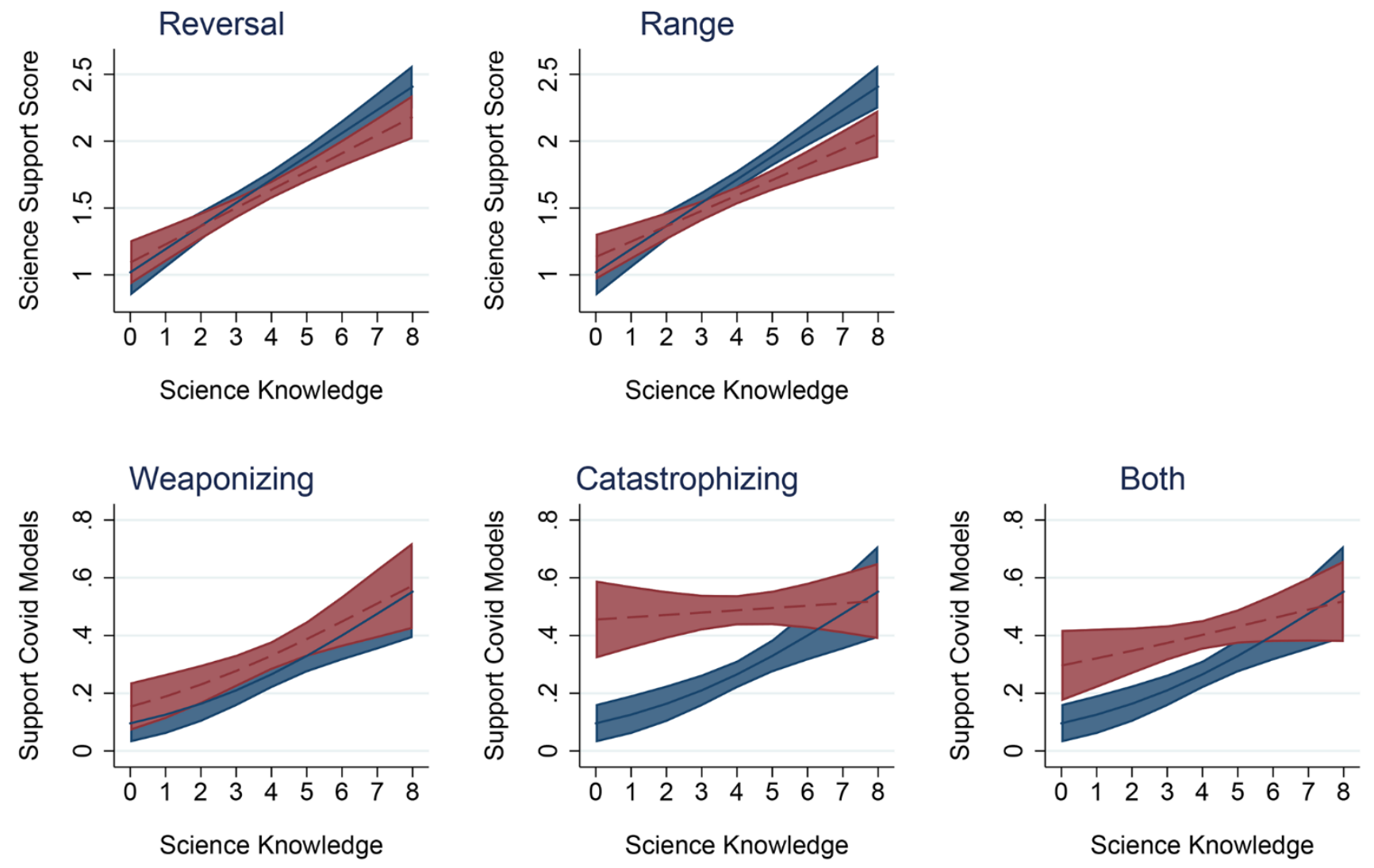

\section{Control - - - - Treatment}

Fig. 6. Treatment effects by science knowledge. The top row presents the effect of the reversal and range treatments from experiment 3 on the science support score. The bottom row presents the effects of the weaponizing, catastrophizing and combined treatments from experiment 4 on support for using COVID-19 models to guide reopening. Shaded bands present $90 \%$ confidence intervals around point estimates. 